\title{
Abundance and density of a Columbian black-tailed deer population on an urban island
}

\author{
Robert P. Wingard ${ }^{1}$, Paul R. Krausman $2,{ }^{*}$, and Ruth Milner ${ }^{1}$ \\ ${ }^{1}$ Washington Department of Fish and Wildlife, La Corner, WA 98257 \\ 2 University of Arizona, Tucson, AZ 85721
}

\begin{abstract}
Methods to estimate abundance and density of Columbian black-tailed deer (Odocoileus hemionus columbianus) are limited. Regional wildlife managers are concerned that Columbian black-tailed deer on Whidbey Island, Washington, USA, exceed carrying capacity. Research on small islands in the Pacific Northwest reports high deer densities; however, these islands are smaller and less complex than Whidbey Island, and have fewer mortality sources. Our objective was to estimate the abundance and density of Columbian black-tailed deer on Whidbey Island by using road-based spotlight surveys in a distance sampling framework. We conducted spotlight surveys from 12 January 2015 to 23 January 2015 starting $\leq 1 \mathrm{~h}$ after sunset and continuing to 23:00. The deer population of Whidbey Island is estimated to be 2744.5 individuals $\left(6.2 \mathrm{deer} / \mathrm{km}^{2}\right)$, lower than estimated densities of deer on smaller islands in the region. Density varied across the different sections of Whidbey Island. Road-based spotlight surveys in a distance sampling framework are a useful tool for estimating deer populations in regions where traditional monitoring methods are not practical. This research offers baseline estimates for the deer on Whidbey Island and provides a repeatable procedure to estimate abundance and density.
\end{abstract}

Resumen.-Los métodos para estimar la abundancia y la densidad del ciervo cola negra de Columbia (Odocoileus hemionus columbianus) son limitados. Los encargados de la reserva de vida sivestre regional están preocupados porque el ciervo Odocoileus hemionus columbianus de la isla Whidbey (Washington, E.U.) exceda su capacidad de carga. La investigación llevada a cabo en pequeñas islas del noroeste del Pacífico reportan una alta densidad de ciervos. Sin embargo, estas islas son más pequeñas y menos complejas que la isla Whidbey y con menos fuentes de mortalidad. Nuestro objetivo fue estimar la cantidad y la densidad de ciervos Odocoileus hemionus columbianus en la isla Whidbey utilizando el método de muestreo a distancia que se basa en detección de individuos a pie de carretera. Llevamos a cabo el muestreo desde el 12 al 23 de enero del 2015, comenzando $\leq 1$ hora después de la puesta del sol y continuando hasta las 2300 horas. La población de ciervos en la isla Whidbey se estima en $2744.5\left(6.2\right.$ venados $\left./ \mathrm{km}^{2}\right)$, una densidad inferior a la estimada en las islas más pequeñas de la región. La densidad varió en las diferentes zonas de la isla Whidbey. Los métodos de detección de individuos a pie de carretera, en un marco de muestreo a distancia son una herramienta útil para estimar las poblaciones de ciervos en regiones donde los métodos tradicionales de monitoreo no son viables. Esta investigación ofrece estimados de los ciervos de la isla Whidbey y un procedimiento replicable para estimar abundancia y densidad.

One of the first steps to properly manage wildlife is to obtain reliable knowledge of the species (White and Bartmann 1983, Roseberry and Woolf 1991). The lack of information about a species is a problem most often associated with imperiled species, for which there are too few individuals to provide consistent inference or the individuals are too difficult to detect (Campbell et al. 2002). But sometimes, well-studied and common species also pose management challenges due to limited data. This is the case with Columbian black-tailed deer (Odocoileus hemionus columbianus) on Whidbey Island, Washington, USA. This population has not been studied, and biologists with the Washington Department of Fish and Wildlife (WDFW) are interested in obtaining more information concerning deer on the island so informed decisions can be made about their management (R. Milner [WDFW] personal communication).

Wildlife managers in the region suggest that deer may be above carrying capacity, especially social carrying capacity. There are

\footnotetext{
*Corresponding author: krausman@email.arizona.edu
} 
fewer mortality sources for deer on Whidbey Island than in other regions Columbian black-tailed deer inhabit. The only natural predators observed during this study were coyotes (Canis latrans). The other sources of mortality for deer on Whidbey Island are anthropogenic: hunting or wildlife-vehicle collisions. Other regions, with fewer anthropological influences and more connectivity than exists on Whidbey Island, have more natural predators, including American black bears (Ursus americanus), mountain lions (Puma concolor), bobcats (Lynx rufus), and wolves (Canis lupus). The dearth of predators on Whidbey Island, combined with the lack of severe winters due to the strong marine influence, suggests that there may be lower natural mortality rates than in other regions. Deer on Whidbey Island, however, have been exposed to disease, specifically hair loss syndrome from a nonnative chewing louse (Damalinia [Cervicola]) (http://www.seattlepi.com/local /sound/article/Whidbey-Island-deer-stricken -by-deadly-hair-loss-1401312.php). Research conducted on other herds suggests that hair loss syndrome can exacerbate decreased fawn recruitment, leading to population growth potential not being realized (Bender and Hall 2004, Bildfell et al. 2004, McCoy et al. 2014). However, effects of hair loss syndrome on the Whidbey Island deer population are unknown.

There are limited methods of estimating abundance and density of Columbian blacktailed deer at scales appropriate for management. Traditional population survey methods, such as aerial counts, are often ineffective in the dense forests these deer inhabit. Aerial surveys using forward-looking infrared sensing, while useful for white-tailed deer (Odocoileus virginianus), are not effective in the regions Columbian black-tailed deer inhabit because the tree canopy in those regions is too high and dense (Naugle et al. 1996). Fecal pellet surveys and direct-observation-whilewalking distance sampling transects can be useful, but they are also time consuming, and in some circumstances it can be difficult to obtain the consent of many small-property owners.

Research has been conducted on Columbian black-tailed deer on neighboring Whidbey Island, but little information from those islands is applicable because Whidbey Island is much larger and more complex. Research on neighboring islands reports higher deer densities than have been reported in mainland deer populations (Table 1). On small islands, deer density is as high as 105 deer $/ \mathrm{km}^{2}$ (Martin et al. 2011), but most density estimates range between 20 and 40 deer $/ \mathrm{km}^{2}$ (Long et al. 2009). Mainland density estimates range from 0.5 to 16 deer $/ \mathrm{km}^{2}$ (Brown 1961, Smith 1968, 1987, Happe 1982, Bender et al. 2004b; Table 1). Mainland density estimates may not be applicable to Whidbey Island deer populations because of differences in environmental and anthropogenic conditions.

Traditional road-based spotlight surveys for deer are conducted without a method of estimating the detection rate of the spotlight survey; they simply provide a population index, which is of little use to managers (Anderson 2001). Additionally, with certain analysis methods, road-based spotlighting has high variability, leading some to question its viability as a wildlife surveying technique (Collier et al. 2007, 2013). By conducting the spotlight surveys within a distance sampling framework, however, researchers can estimate detection rates, accounting for this criticism, and can also provide estimates of abundance and density instead of indices (Buckland et al. 2001). Road-based spotlight surveying conducted in a distance sampling framework is a method that has seen widespread use by managers and researchers of many species of deer, from sika deer (Cervus nippon) in Japan to white-tailed deer in the eastern United States to various deer species in the United Kingdom (Gill et al. 1997, Heydon et al. 2000, Koganezawa and Li 2002, Ward et al. 2004, McShea et al. 2011).

Bias associated with conducting spotlight surveys from roads can arise when deer are either repelled from roads (Rost and Bailey 1979, Bender et al. 2004a) or attracted to roads (Gill et al. 1997, Ward et al. 2004). These biases can be reduced under certain conditions-specifically, if the location of roads is not influenced by variables that affect the study species' distribution or abundance (i.e., topography, vegetation distribution, streams; McShea et al. 2011, Anderson et al. 2013). Whidbey Island has very gentle topography and no permanent streams. The roads on the island have very little relation to the topography of the island, and they rarely represent drastic changes in land cover associated with the road or with the road serving 


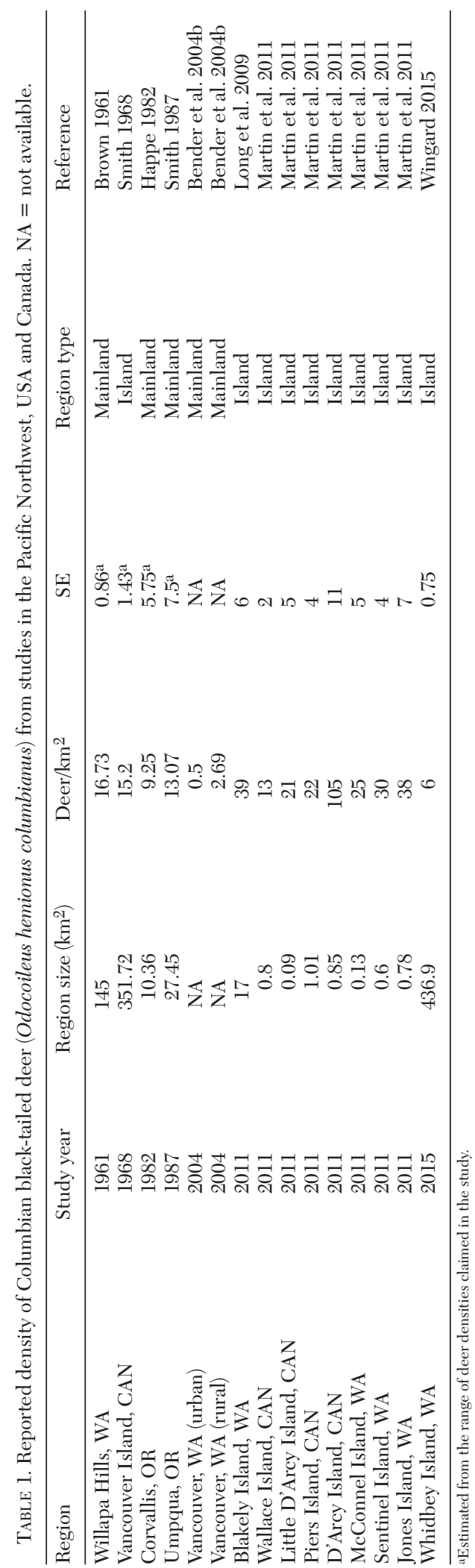

as a boundary between land cover changes. The ability to cover large areas in shorter periods of time has substantial benefits, including increased likelihood of the population being closed over the sampling period.

A primary method to reduce potential bias prior to sampling is to use road segments as transects, stratified into different cover types in proportion to the availability of the different sections of the landscape (Buckland et al. 2001). Because high traffic rates can lead to increased road avoidance by deer, road segments with lower traffic rates should be used whenever possible in urban areas or areas with limited numbers of roads (Rost and Bailey 1979, Forman et al. 2003).

With analysis software such as Distance, the bias introduced by animals moving away from the transect can be controlled (Thomas et al. 2010, McShea et al. 2011). Within the analysis there are 2 methods to account for this bias: either censor the observations closest to the road or expand the first distance interval (Buckland et al. 2001, McShea et al. 2011). Road-based spotlight surveying within a distance sampling framework is the best field sampling method for this study area because it can produce adequate sample size, something that other distance sampling survey methods (i.e., aerial, fecal pellet, walking) cannot do in a timely manner. Fecal pellet transects and walking transects using distance sampling have been successfully used on nearby islands, but these methods are not feasible in areas such as Whidbey Island with numerous tracts of private land. Areas of predominantly private land with numerous land owners are especially problematic, because of the need to obtain permission from each land owner for access. This task is more difficult in a region with many nonpermanent residents and few landline telephones, or in regions with landowners that simply do not allow access.

The creation of fully formed detection functions for objects along a transect requires a minimum of approximately 45 observations for each stratum (in this case north, central, and south sections of Whidbey Island [Buckland et al. 2001]). Road-based spotlight distance sampling provides the best opportunity to gather the amount of data needed for the analysis. Additionally, road-based spotlight surveys can provide information at lower 


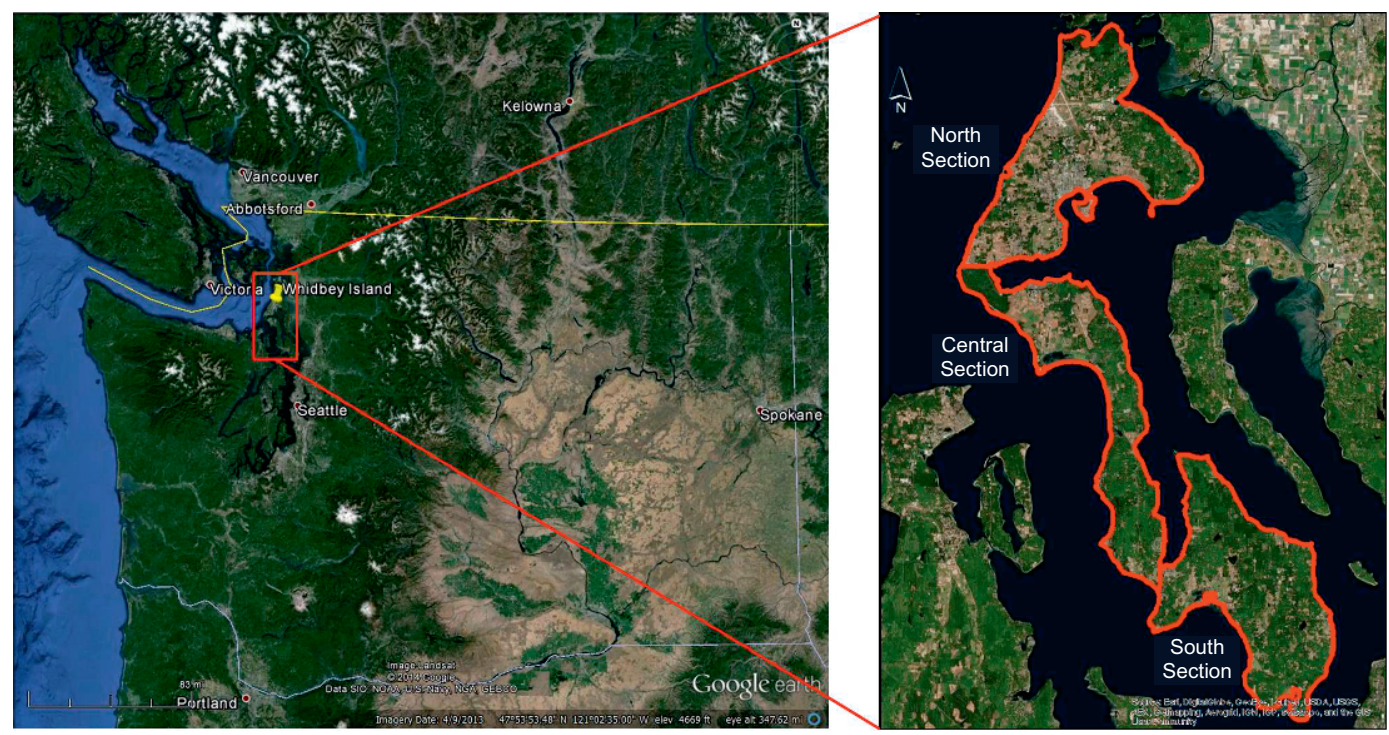

Fig. 1. Whidbey Island, Washington, USA.

cost than can other abundance estimation techniques such as aerial surveys, fecal pellet distance sampling, and walking distance sampling (Gill et al. 1997, Uno et al. 2006, Amos et al. 2014).

Our objective was to determine the abundance and density of deer on Whidbey Island. We predicted that the density of Columbian black-tailed deer on Whidbey Island would be similar to the density on Vancouver Island ( 15.2 deer $/ \mathrm{km}^{2}$; Smith 1968), the other large island in the area.

\section{Methods \\ Study Area}

Whidbey Island is in northwest Washington (Fig. 1). The island is roughly $88.0 \mathrm{~km}$ by 2.4-19.0 km with a north-south orientation, and it occupies $436.9 \mathrm{~km}^{2}$. The overall climate of Whidbey Island is Pacific Northwest temperate with cool, wet winters and warm, dry summers. The major climatic influence on the island is the rain shadow effect from the Olympic Mountains west of the island. The rain shadow effect is most dominant on the central and northern portions of the island due to the predominant storm path from the southwest, with average annual rainfall on the central portion of the island being $510 \mathrm{~mm}$. This average increases to $910 \mathrm{~mm}$ on the southern portions of the island and
$810 \mathrm{~mm}$ on the northern portions of the island. The difference in rainfall, combined with human and agricultural development, influences the vegetation differences between the northern, central, and southern areas of the island.

Whidbey Island's flora is varied due to differences in rainfall and human disturbance. We used the land cover data set established by researchers from the United States Geological Survey (USGS GAP Analysis) to classify the 33 ecological systems or land uses: 11 forest, 4 shrub and grassland, 6 marsh, 3 rock or barren, 2 open water, 4 human development, and 3 agriculture. The forests are warm and cool temperate, temperate flooded and swamp, and recently logged forests. The shrub and grasslands are temperate and boreal grassland meadow, and scrub. The marshes are temperate and boreal fresh and saltwater meadows and marshes. Open water consists of fresh and salt water. Human development consists of developed and urban areas, and gravel quarry mining. The agriculture consists of pasture and crops. Mesocarnivores, including striped skunk (Mephitis mephitis), raccoon (Procyon lotor), and red fox (Vulpes vulpes), inhabit the island, but coyotes are the only predators of deer. Domestic livestock, including cattle, sheep, goats, llamas, alpacas, and horses, are prevalent throughout the island. 
Locations of Deer Observations

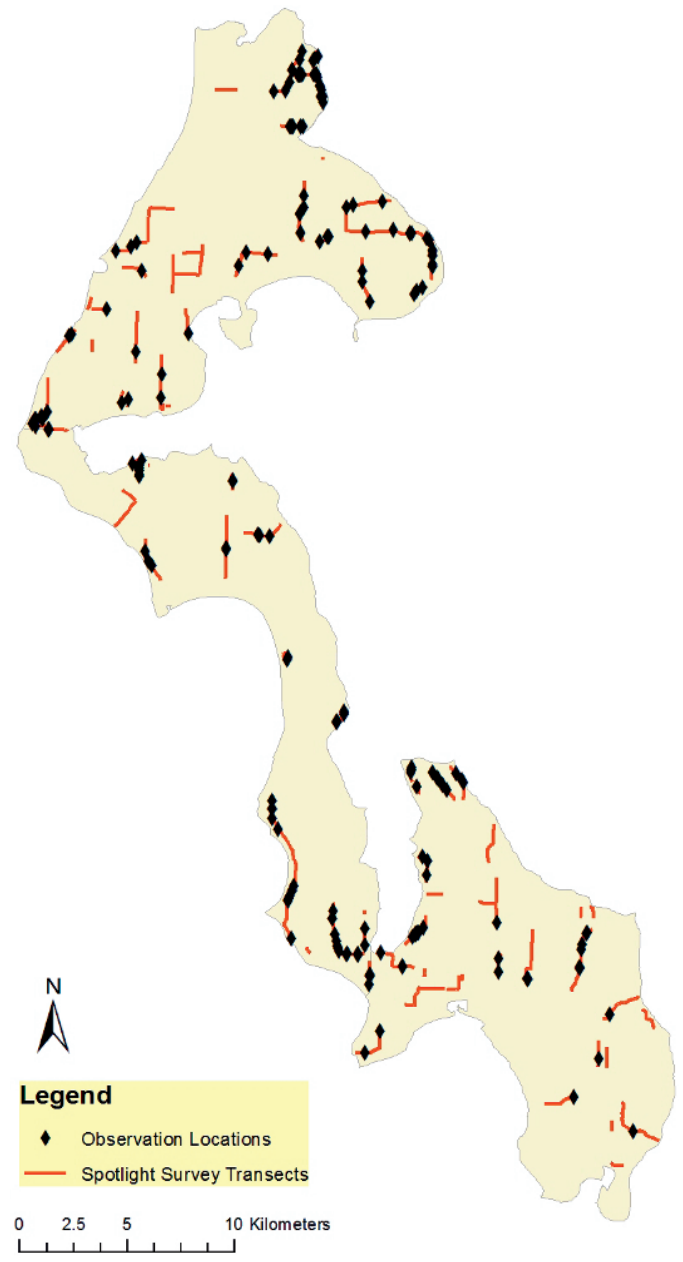

Fig. 2. Locations of spotlight transects and deer observations, January 2015, Whidbey Island, Washington, USA.

The topography of Whidbey Island is generally tame (elevation varies from sea level to $148 \mathrm{~m}$ ) and is devoid of large mountains or continuous steep slopes, with the exception of the coastline, where there are large bluffs.

For the purposes of this study we divided the island into 3 sections: north, central, and south. The north section of the island (166 $\mathrm{km}^{2}$ ) extends from the west end of Penn Cove to the northern end of the island. The central section $\left(122 \mathrm{~km}^{2}\right)$ extends from the west end of Penn Cove south to Freeland. The south section $\left(152 \mathrm{~km}^{2}\right)$ extends from Freeland to the southern end of the island.
The 3 sections differ from each other in environmental and anthropogenic conditions.

The human population of Whidbey Island is 62,845 (U.S. Census Bureau 2010). The population is centered in Oak Harbor, in the north section; over half the island's population resides in the north section (U.S. Census Bureau 2010). The north section of the island is more urbanized than the rest of the island, whereas the central and south sections are more rural. The human population density is $221 / \mathrm{km}^{2}$ in the north section, $102 / \mathrm{km}^{2}$ in the central section, and $90 / \mathrm{km}^{2}$ in the south section (United States Census Bureau 2010).

Portions of the island are protected through county and state parks, conservation easements, and land trusts. The largest limitedaccess landowner on the island is the Department of Defense, with $23 \mathrm{~km}^{2}(5 \%)$. Whidbey Island Naval Air Station is in the north section of the island, with smaller outlying holdings.

There are $1327 \mathrm{~km}$ of roads across Whidbey Island, and overall road density is 3.0 $\mathrm{km} / \mathrm{km}^{2}$. The distribution of roads is not uniform. Across the 3 sections of the island, there is a gradient of road density from $3.4 \mathrm{~km}$ $/ \mathrm{km}^{2}$ in the north to $3.0 \mathrm{~km} / \mathrm{km}^{2}$ in the south to $2.7 \mathrm{~km} / \mathrm{km}^{2}$ in the central section.

\section{Field Methods}

We conducted road-based spotlight surveys on Whidbey Island to gather the data required to perform distance analysis. We developed survey routes on the 3 sections of the island on 150 road transects, varying in length from $62 \mathrm{~m}$ to $3222 \mathrm{~m}$ (Fig. 2). The transects represented $10 \%$ of the available roads in each section; therefore, sampling effort was weighted by the length of roads in each section. We selected transect routes in proportion to the surrounding land cover types in each region and so as to increase the geographic spread of the survey.

Starting from the surveying protocol established by the National Park Service for studying deer in the National Capitol Region, Washington, DC, we adapted the protocol to our logistical constraints in conducting the surveys (Bates 2006). The protocol uses 4 people/vehicle: 1 driver, who also observes the transect line (road); 1 data recorder; and 2 spotlight operators, 1 on each side of the vehicle. The survey vehicle is driven at approximately $25 \mathrm{kph}$, to maximize detection rates 
while providing for the safety of the observers on public roads.

Clear survey weather was experienced throughout the sampling period. By conducting sampling in winter, we took advantage of the lack of leaves on most understory plants in the region, which increased detection probability of deer.

We used a 2004 Toyota 4Runner as the survey vehicle, with 1 driver and 2 observers with spotlights in the back seats. The surveys began $\leq 1 \mathrm{~h}$ after sunset and finished before 23:00 (to reduce the potential for complaints among island residents). The driver remained the same throughout the surveys. There were 5 different observers for this study, but 2 participated every night. The third observer participated on 8 nights, and the final 2 observers participated on 1 night each.

When a deer was detected, we stopped the vehicle and recorded the location of the vehicle as a waypoint in a global positioning system unit (Garmin Oregon 600t, Olathe, KS, USA). We recorded the following measurements for each observation: transect identification, island section, time, observer, distance (m) to the deer, bearing to the deer, group size, sex (if possible), and vegetation association. We determined group size by proximity of deer to each other and behavioral cues. Additionally, deer in one group were no more than half the distance from the closest deer in their own group to the closest deer of a neighboring group (Stainbrook 2011). We recorded weather information for each transect at the beginning of the evening's survey (Happe 1982, McShea et al. 2011, Stainbrook 2013).

We organized sampling so the different regions of the island were surveyed in reverse order to the previous sampling effort for that region. For example, if the first survey of a region followed the route north to south, the second survey would follow the route in reverse order, south to north. This allowed the different portions of the route to be surveyed at opposite times of the evening.

We imported observer locations into ArcGIS (version 10.2, ESRI, Redlands, CA) with the distance and bearing to the deer. We generated locations of the observed deer using the distance bearing to line tool, then the line end to point tool. Then, using the near tool, we determined the distance between each deer location and the transect, generat- ing the perpendicular distance data required for distance sampling analysis (Pierce 2000).

\section{Statistical Analysis}

We imported survey data, including group size, cover type, observer, and majority land cover type of the transect, into program Distance (Thomas et al. 2010). We estimated abundance and density separately for the 3 sections of the island and for the entire island using the Multiple Covariate Distance Sampling engine within the software (Thomas et al. 2010).

We examined the data collected during the spotlight surveys as histograms using Program R 2.15.2 (R Development Core Team 2014). There was evidence of deer movement or bias away from the transect. To account for this bias, we grouped observations into distance intervals (Buckland et al. 2001, Bates 2006). For the island-wide model (global model), the first distance interval was expanded to include sightings at a distance of $\leq 20 \mathrm{~m}$ (Ward et al. 2004, Bates 2006, McShea et al. 2011). The data for the global model were truncated to $100 \mathrm{~m}$ to remove approximately 12 long observations (i.e., $>100 \mathrm{~m}$ ). This is permissible, as these long observations contribute little to fitting the detection function and decrease the precision of estimates (Buckland et al. 2001). We examined data for each of the 3 regions separately using histograms to determine appropriate truncation points and to assist us in deciding whether to expand the first distance interval.

The parameters measured for each observation were examined to determine any correlation between group size, because correlations can be troublesome during later analysis in Distance. There was evidence of correlation between observed group size and distance from transect $(r=0.21, P=0.002)$. The correlation caused an overestimation of the value of cluster sizes, because large clusters are more likely to be observed than small clusters, eventually leading to an overestimation of density and abundance (Buckland et al. 2001). To address this bias, we estimated group size using a size-biased regression of the natural log of cluster size against estimated detection if the regression was significant at $\alpha=0.05$.

Models were fit to the data using different key functions, including half-normal and 


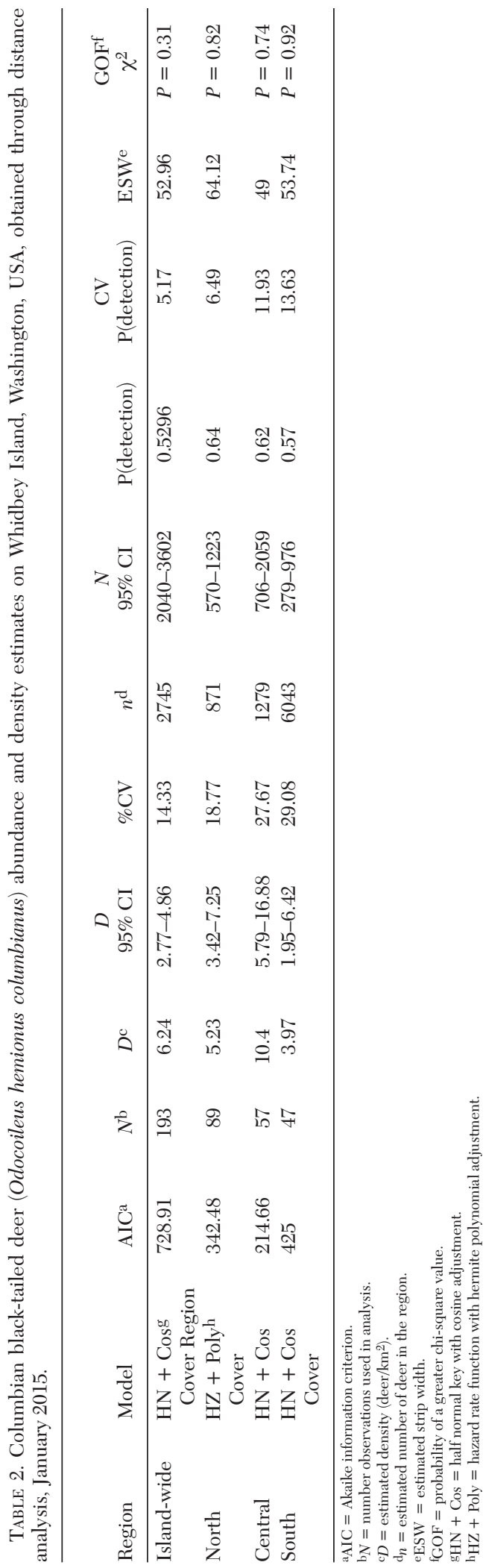

hazard rate. Key functions describe the shape of the detection function curve, while the expansion adjustment describes the scale of the detection function curve (Buckland et al. 2001). By using the Multiple Covariate Distance Sampling analysis engine, available covariates were included in the model in a stepwise manner, and their appropriateness was determined by reductions in the Akaike information criterion (AIC; Burnham and Anderson 2002) and coefficient of variation. The cover type where deer were observed was consistently selected as an appropriate covariate in the modeling process. Other covariates attempted in the modeling included region and majority land cover type of the transect. When majority land cover type of each transect was included in the model, the model failed to converge. This outcome is likely a function of the limited number of observations in specific land cover types and the large number of parameters in the model. The attempted covariates were added in a stepwise manner. The resultant models were compared to other models by using AIC and coefficient of variation and were either included or dropped.

We assessed model fit using 3 main methods: coefficient of variation $<20 \%$, lowest AIC scores, and detection probability variation $<30 \%$ (Buckland et al. 2001, Bates 2007). Once candidate models were selected, the analysis was run again with nonparametric boot-strapping with 1000 resamples to estimate the variance within the models.

\section{Results}

\section{Field Sampling Results}

Whidbey Island was surveyed 4 times over 10 nights from 12 January 2015 to 23 January 2015 . We surveyed $500 \mathrm{~km}$ of roads and recorded 208 observations of deer (Fig. 2).

\section{Statistical Results}

We first estimated island-wide abundance and density by pooling observations from all regions for the analysis. The half-normal function with cosine adjustment consistently provided better fit to the data than the hazardrate function with hermite polynomial adjustment. Grouping the data into intervals with a large first interval provided better model fit than ungrouped data did. Additionally, 
TABLE 3. Competing models for Columbian black-tailed deer (Odocoileus hemionus columbianus) densities for different regions of Whidbey Island, Washington, USA, obtained through distance analysis, January 2015.

\begin{tabular}{|c|c|c|c|c|c|c|}
\hline Region & Competing models & $\Delta \mathrm{AICa}$ & AIC & ESWb & $D^{\mathrm{c}}$ & $D C V$ \\
\hline Island-wide & $\mathrm{HN}^{\mathrm{d}}+$ Cover Stratified & 0 & 725.92 & 53.16 & 5.768 & 0 \\
\hline Island-wide & HN + Cover Region & 2.99 & 728.91 & 52.96 & 6.038 & 0.124 \\
\hline North & $\mathrm{HZ}+$ Polye & 0 & 342.18 & 66.89 & 4.935 & 0.177 \\
\hline North & Cover & 0.30 & 342.48 & 64.12 & 5.138 & 0.176 \\
\hline North & Uniform & 1.20 & 343.38 & 64.07 & 4.844 & 0.221 \\
\hline North & $\mathrm{HN}+\operatorname{Cos}^{\mathrm{f}}$ Truncated & 2.23 & 344.41 & 60.17 & 4.984 & 0.241 \\
\hline Central & $\mathrm{HN}+\mathrm{Cos}$ & 0 & 214.66 & 49.27 & 9.5 & 0.254 \\
\hline Central & $\mathrm{HZ}+$ Poly & 0.81 & 215.47 & 42.96 & 11.19 & 0.336 \\
\hline Central & Uniform & 1.62 & 214.66 & 49.45 & 9.38 & 0.258 \\
\hline South & $\mathrm{HN}+\mathrm{Cos}$ Truncated at $95 \mathrm{~m}$ & 0 & 415.18 & 53.74 & 4.4 & 0.277 \\
\hline South & $\mathrm{HZ}+$ Poly Truncated at $95 \mathrm{~m}$ & 1.23 & 416.41 & 58.89 & 4.246 & 0.298 \\
\hline South & $\mathrm{HN}+$ Cos Cover & 0 & 415.18 & 53.74 & 4.4 & 0.277 \\
\hline
\end{tabular}

aAC $=$ Akaike information criterion

bESW $=$ estimated strip width.

${ }^{\mathrm{c}} \mathrm{D}=$ estimated density $\left(\right.$ deer $\left./ \mathrm{km}^{2}\right)$.

$\mathrm{d} H \mathrm{HN}=$ half normal key.

${ }^{\mathrm{e}} \mathrm{HZ}+$ Poly $=$ hazard rate function with hermite polynomial adjustment.

$\mathrm{f}_{\mathrm{Cos}}=$ cosine.

truncating the data to $100 \mathrm{~m}$ provided increased precision while censoring 12 observations from the analysis.

Models that included the cover type where deer were observed consistently performed better (based on AIC and coefficient of variation) than other models (Tables 2, 3). The inclusion of other covariates in the models did not improve the AIC value of the models.

There were 2 competing models, both using the half-normal key function with cosine expansion and cover type where deer were observed as a covariate. The models differed in one key way: the method of accounting for the different regions. In the first model, region was included as a covariate. The second model stratified the analysis by region. The results of the 2 models are similar in their estimates but differ in their accuracy.

We proceeded with the model that accounted for region by including region as a covariate, because the AIC value was similar but the model had a lower percent coefficient of variation, especially compared to the precision statistics for each region in the stratified model. This model provided a detection function that fit the grouped data. According to this model, the island-wide density of Columbian black-tailed deer on Whidbey Island was $6.2 \mathrm{deer} / \mathrm{km}^{2}$, extrapolated to a total population of 2744 (Table 2). Three percent of Whidbey Island was within the effective strip width of $53 \mathrm{~m}$, and $5 \%$ of Whidbey Island was within the truncation distance of $100 \mathrm{~m}$.
The global analysis indicated the importance of the different regions of the island and their different influences on deer density. We proceeded to separate the data into the different regions and then analyzed each region separately to increase the precision of the estimates and gain a deeper understanding of the regional differences in deer density on Whidbey Island.

There were 96 deer observations in the north. Examining a histogram of the data suggested that a truncation distance of $100 \mathrm{~m}$, a censoring of 7 observations, and a large first interval would provide increased model fit. The north section had 2 competing models. The first model, which used a hazard-rate function with hermite polynomial expansion, provided the lowest AIC and a reasonable coefficient of variation (0.18). The second model was also a hazard-rate function with hermite polynomial expansion, but with the addition of cover type where deer were observed as a covariate. This model provided a higher AIC (0.3) and an equal coefficient of variation $(0.18)$. The model without cover type constrained the parameters; therefore, the model including cover type, which had no such issues, was selected. This model provided a density estimate of 5.2 deer $/ \mathrm{km}^{2}$ for a population of 836 deer in the north (Table 2). Seven percent of the north section of the island was sampled within our truncation distance of $100 \mathrm{~m}$, and $4 \%$ of the north section was within the effective strip width of $64 \mathrm{~m}$. 
There were 57 observations of deer in the central section of the island. Examining a histogram of the observations suggested a truncation distance of $80 \mathrm{~m}$, a censoring of 3 observations, and the grouping of data into intervals of 10 . The data collected on the central section was best described by a halfnormal function with a key expansion and no covariates. This model had the lowest AIC (214.66), nearly the same coefficient of variation (0.25), and better goodness of fit $(P=0.74$; Table 2$)$. This model estimated a density of 10.8 deer $/ \mathrm{km}^{2}$, which extrapolates to an abundance of 1311 deer in the central section (Table 2). Three percent of the central section of the island was within the truncation distance of $80 \mathrm{~m}$, and $2.5 \%$ of the central section was within the effective strip width of $49 \mathrm{~m}$.

There were 55 observations of deer in the south section of the island. Examining a histogram of the observations suggested a truncation distance of $95 \mathrm{~m}$ and a censoring of 7 observations while not suggesting expansion of the first interval. The data collected on the south section of the island were best described by a half-normal function with a cosine expansion and with cover type as a covariate. This model had the same AIC (415.8) and the same coefficient of variation (0.28) as another model with the same function and expansion without the cover type covariate, but this model did not need to have its parameters constrained to obtain monotonicity (Table 2). The selected model estimated the density of deer in the south as 4 deer $/ \mathrm{km}^{2}$, which extrapolates to an abundance of 604 deer (Table 2). Seven percent of the south section of Whidbey Island was within the truncation distance of $95 \mathrm{~m}$, and $4 \%$ of the south section was within the effective strip width of $54 \mathrm{~m}$.

\section{Discussion}

The estimated density of Columbian blacktailed deer on Whidbey Island is closer to the range of deer densities reported for mainland areas and Vancouver Island than densities reported for small, nearby islands (Table 1). While the different studies estimated density using a variety of methods, there is a clear trend of higher densities on small islands of the San Juan Archipelago and the Canadian Gulf
Islands compared to mainland or large island population densities (Table 1). Columbian black-tailed deer density on small islands has been calculated in several studies (Long et al. 2009, Martin et al. 2011) and ranges from 13 to $38 \mathrm{deer} / \mathrm{km}^{2}$, except on D'Arcy Island, which had a density of 105 deer $/ \mathrm{km}^{2}$ (Martin et al. 2011). Density, however, was estimated by counting fecal pellet groups and then corrected based on fecal pellet group counts from an island with a known deer population (Martin et al. 2011). Deer densities estimated via walking distance sampling on Blakely Island were up to 39 deer $/ \mathrm{km}^{2}$ (Long et al. 2009); however, these islands are much smaller than Whidbey Island, with none of the islands studied being larger than $17 \mathrm{~km}^{2}$.

Mainland estimates of Columbian blacktailed deer density around Vancouver, Washington, varied by the level of anthropogenic disturbance. In urban regions, deer density was estimated to be $<1$ deer $/ \mathrm{km}^{2}$, while in adjacent rural regions, deer density was estimated to be 2.7 deer $/ \mathrm{km}^{2}$ (Bender et al. 2004b). Research on sympatric Columbian black-tailed deer and Columbian white-tailed deer (Odocoileus virginianus leucurus) in Oregon's Umpqua River valleys, generated Columbian black-tailed deer densities ranging from 1 to $30 \mathrm{deer} / \mathrm{km}^{2}$, with an average of 13.1 deer $/ \mathrm{km}^{2}$ among 9 study sites, but these estimates were generated via spotlight census methods that are problematic (Smith 1981, 1987, Collier et al. 2007, 2013). Research conducted around Corvallis, Oregon, also estimated deer density with spotlight census methods (Happe 1982). Estimated density varied by season and land cover type, but ranged between 1 and $26 \mathrm{deer} / \mathrm{km}^{2}$, with most of the estimates falling under 8 deer $/ \mathrm{km}^{2}$. The average density observed was $\sim 9$ deer $/ \mathrm{km}^{2}$. The only land cover type that had density $>10$ deer $/ \mathrm{km}^{2}$ was pasture in winter and spring. Additionally, densities of deer were lower in forested areas than in pasture and developed areas, likely due to an either-sex hunt in forested areas (Happe 1982). Research conducted by WDFW in the 1950s in the Willapa Hills region of Washington estimated deer abundance and density using fawn: female:male proportions and hunter harvest information to estimate an average density across seral stages of 16.7 deer $/ \mathrm{km}^{2}$ (Lauckhart 1950; Brown 1961, p. 56; WDFW 2014). 
On Vancouver Island, researchers reported a density range of $11.3-17.1$ deer $/ \mathrm{km}^{2}$ (Smith 1968). However, the researcher acknowledged that the numbers may be biased given the data collection methods concerning estimated fawn:female:male proportions from deer counts in early seral stage areas and the use of hunter reports, which are acknowledged to be suspect (Lauckhart 1950, Smith 1968, McCullough et al. 1994).

We attribute the higher densities of the older studies to one key factor: use of techniques (i.e., spotlight census methods) that do not account for imperfect detection and that focus on areas with many deer, leading to overestimation of density (Smith 1968, 1987, Happe 1982, McCullough et al. 1994, Collier et al. 2007). Recent estimated densities are likely more robust to variation and more accurate. These recent studies suggest a gradient from low-density mainland regions to high-density islands (Bender et al. 2004b, Long et al. 2009, Martin et al. 2011).

Differences in estimated deer density across the 3 sections of Whidbey Island were striking, with the central section of the island having a much higher estimated density than the north or south sections. However, when the abundance estimates from the independently analyzed island sections were summed to determine total abundance for the island, the estimate was very close to the estimated abundance from the global model (2744 to 2753 deer). Because the global model also accounted for region, this suggests that the regional differences across the island are playing a major role in the varying densities of Columbian black-tailed deer across Whidbey Island.

The key differences between the sections are the level of urbanization and the intensity of the Olympic Rain Shadow effect. The central and south sections of Whidbey Island are less than half as densely populated as the north section of the island is; the north section of Whidbey Island has a human population density of $221 / \mathrm{km}^{2}$, while the central section has a density of $102 / \mathrm{km}^{2}$ and the south section has a density of $89 / \mathrm{km}^{2}$. The differences in human population density alone are not enough to explain the variation in deer density, as estimated deer density on the south section is much lower than the estimated density on the central section (4 vs. $\left.10.5 \mathrm{deer} / \mathrm{km}^{2}\right)$.
The intensity of the Olympic Rain Shadow effect is likely to play a key role in the variation of deer density across the island. The average rainfall on the central section of Whidbey Island is nearly half that of the south section (510 vs. $910 \mathrm{~mm}$; National Oceanic and Atmospheric Administration, https://www .weather.gov). This large variation in rainfall drives differences in the land cover types, with drier forests and more open areas dominating the central section of the island and wetter forests and fewer open areas dominating the south section. The north section of the island has less rain than the south section and more open areas, but the high human population may be limiting the deer population in the north, as other studies have observed fewer Columbian black-tailed deer in more urban areas, with few exceptions (McCullough et al. 1997, Bender et al. 2004a, 2004b).

Though we did not generally observe evidence of movement prior to detection in this study, deer were seldom observed directly on transects. This was to be expected as all transects were paved public roads. For deer, there is little biological value in being directly on the road. Therefore, any detections directly on the transect would be deer moving from one side of the road to the other, not remaining on the road for substantial periods of time. Accounting for this in the analysis by expanding the first distance interval had the effect of moving the theoretical location of the transect to include the road surface and the edge habitat directly off the road, as the detection probability in the first distance interval is assumed to be 1 . The expansion of the first distance interval also improved the model fit in the analysis.

There is conflicting evidence for the relationship between density of deer and roads for other regions and deer species (Rost and Bailey 1979, Gill et al. 1997, McCoy and Gallie 2005, Stainbrook 2011, Munro et al. 2012, Anderson et al. 2013). Different studies reported both higher and lower densities of the study species farther from roads (McCoy and Gallie 2005, Stainbrook 2011, Munro et al. 2012, Anderson et al. 2013). On Whidbey Island, the number of deer-vehicle collisions has historically been $>150$ annually (R. Milner personal communication). However, there is limited information on whether increased wildlife-vehicle collisions lead to 
road avoidance by wildlife (Grosman et al. 2011). Additionally, poaching is a limited issue on the island, and local WDFW enforcement officers do not view it as a large enough problem to lead to road avoidance (R. Downes, WDFW enforcement, personal communication). If deer on Whidbey Island are avoiding roads, the estimated detection probability will be biased high, leading to a negative bias in density and abundance, meaning the estimates are likely low. If deer are attracted to roads, the detection probability may be biased low, leading to an overestimation of density and abundance.

One of the more recent advances in distance sampling addresses the nonrandom distribution of animals or density gradients around the transect (Marques 2007, Marques et al. 2013). Recent work has combined independent estimates of distribution in relation to transects with distance sampling to reduce the bias caused by either avoidance of or attraction to roads (Marques 2007, Stainbrook 2011, Marques et al. 2013). These studies attempt to determine the direction and magnitude of the bias associated with roads to increase the precision and accuracy of the estimate. Due to logistical constraints, this study was not able to estimate deer density in relation to roads independently. Future research concerning road-based distance sampling of Columbian black-tailed deer should determine the effect that distance to roads has on the density of deer. This will decrease bias introduced by using roads in density and abundance estimates from distance analysis.

Concern about Columbian black-tailed deer overabundance and high density on Whidbey Island is not a new phenomenon. Deer were perceived to be so abundant from the 1930s to the late 1950s that there were attempts to eliminate them from Whidbey Island to protect the strawberry crop (Zem and Wells 1955). This attempt at eradication was unsuccessful, but 400 to 600 deer were harvested annually for 18 years to alleviate the crop damage they caused. This perceived high abundance followed a period of intense industrial logging on the island, which may have led to more beneficial forage conditions for deer (Brown 1961, Smith 1968, Kremsater and Bunnell 1992). More recently, local news reports over the last decade have discussed concerns over the rate of deer-vehicle collisions. Additionally, WDFW has increased hunting opportunity on Whidbey Island by offering a second antlerless tag to hunters in recent years.

Density estimates of deer on Whidbey Island determined by this study range from 4 to 10.5 deer $/ \mathrm{km}^{2}$ depending on region, with an overall density of $6.2 \mathrm{deer} / \mathrm{km}^{2}$. These estimates, along with direct observations, suggest that deer on Whidbey Island are not biologically overabundant. Deer from our observations do not appear to be underweight, and twinning ( 2 neonates) is frequent. Research conducted on nearby islands examining the effect of deer density on biodiversity suggests that deer densities should be maintained at 8 to $10 \mathrm{deer} / \mathrm{km}^{2}$ to permit recovery of native vegetation and allow a diverse group of bird species to thrive (Martin et al. 2011, Arcese et al. 2014). The estimates of deer density from this study place Whidbey Island below or slightly above the threshold, depending on the region: north and south sections of the island are estimated to be below the density threshold for reductions in biodiversity, while the central section is estimated to be at or slightly above the threshold for reduction in biodiversity.

Future research should examine the differences in detection rates between spotlight surveys and surveys that use portable thermal imaging. Much research has been conducted on the applicability of portable thermal imagers in conjunction with spotlight surveys, with promising results (Gill et al. 1997, Focardi et al. 2001, Collier et al. 2007, Morelle et al. 2012). As the price of portable infrared devices continues to decline, infrared imaging may be a more precise alternative to spotlight surveys in the future, causing fewer disturbances of deer and of the public than spotlighting does.

\section{ACKNOWLEDGMENTS}

We thank the Washington Department of Fish and Wildlife for their expertise and logistical support, specifically R. Downs. We appreciate the help of the Island County Sheriff's office. We thank S. Christensen for her knowledge and expertise on road-based distance sampling and for her assistance with analysis. We thank J. Burk, J. Dapper, and 
W. Smith for their assistance with fieldwork. This study was approved by the Institutional Animal Care and Use Committee, University of Montana (054-14PKWB-090914) and funded by the Boone and Crockett Program in Wildlife Conservation at the University of Montana, Missoula, USA.

\section{Literature Cited}

Amos, M., G. Baxter, N. Finch, A. Lisle, and P. Murray. 2014. I just want to count them! Considerations when choosing a deer population monitoring method. Wildlife Biology 20:362-370.

Anderson, C.W., C.K. Nielsen, C.M. Hester, R.D. Hubbard, J.K. Stroud, and E.M. Schauber. 2013. Comparison of indirect and direct methods of distance sampling for estimating density of whitetailed deer. Wildlife Society Bulletin 37:146-154.

Anderson, D.R. 2001. The need to get the basics right in wildlife field studies. Wildlife Society Bulletin 29:1294-1297.

Arcese, P., R. Schuster, L. Campbell, A. Barber, and T.G. Martin. 2014. Deer density and plant palatability predict shrub cover, richness, diversity and aboriginal food value in a North American archipelago. Diversity and Distributions 20:1368-1378.

BAtes, S. 2006. White-tailed deer density monitoring protocol version 1.1: distance and pellet-group surveys. Inventory and Monitoring Program, National Capital Region Network, National Park Service, Washington, DC.

Bates, S. 2007. National Capital Region Network 2007 deer monitoring report. Natural Resource Technical Report NPS/NRCN/NRTR-2009/183, Fort Collins, CO.

Bender, L.C., D.P. Anderson, And J.C. Lewis. 2004a. Annual and seasonal habitat use of Columbian black-tailed deer in urban Vancouver, Washington. Urban Ecosystems 7:41-53.

Bender, L.C., and P.B. Hall. 2004. Winter fawn survival in black-tailed deer populations affected by hair loss syndrome. Journal of Wildlife Diseases 40: 444-451.

Bender, L.C., J.C. Lewis, And D.P. Anderson. 2004b. Population ecology of Columbian black-tailed deer in urban Vancouver, Washington. Northwestern Naturalist 85:53-59.

Bildfell, R.J., J.W. Mertins, J.A. Mortenson, and D.F. Cоттам. 2004. Hair-loss syndrome in black-tailed deer of the Pacific Northwest. Journal of Wildlife Diseases 40:670-681.

Brown, E.R. 1961. The black-tailed deer of western Washington. Biological Bulletin No. 13, Washington Department of Game, Olympia, WA.

Buckland, S.T., D.R. Anderson, K.P. Burnham, J.L. LaAke, D.L. Borchers, and L. Thomas. 2001. Introduction to distance sampling: estimating abundance of biological populations. Oxford Press, New York, NY.

Burnham, K.P., And D.R. Anderson. 2002. Model selection and multimodel inference: a practical information-theoretical approach. 2nd edition. SpringerVerlag, New York, NY.
Campbell, S.P., J.A. Clark, L.H. Crampton, A.D. Guerry, L.T. Hatch, P.R. Hosseini, J.J. Lawler, AND R.J. O’CONNOR. 2002. An assessment of monitoring efforts in endangered species recovery plans. Ecological Applications 12:674-681.

Collier, B.A., S.S. Ditchkoff, J.B. Raglin, and J.M. Sмiтн. 2007. Detection probability and sources of variation in white-tailed deer spotlight surveys. Journal of Wildlife Management 71:277-281.

Collier, B.A., S.S. Ditchkoff, C.R. Ruth, and J.B. RAGLin. 2013. Spotlight surveys for white-tailed deer: monitoring panacea or exercise in futility? Journal of Wildlife Management 77:165-171.

Focardi, S., A.M. De Marinis, M. Rizzotto, and A. PUCCI. 2001. Comparative evaluation thermal infrared imaging and spotlighting to survey wildlife. Wildlife Society Bulletin 29:133-139.

Forman, R.T.T., K. Heanue, J. Jones, F. Swanson, T. Turrentine, T.C. Winter, D. SPerling, J.A. Bissonette, A.P. Clevenger, C.D. Cutshall, et AL. 2003. Road ecology: science and solutions. Island Press, Washington, DC.

Gill, R.M.A., M.L. Thomas, And D. Stocker. 1997. The use of portable thermal imaging for estimating deer population density in forest habitats. Journal of Applied Ecology 34:1273-1286.

Grosman, P.D., J.A.G. Jaeger, P.M. Biron, C. Dussault, AND J.P. Ouellet. 2011. Trade-off between road avoidance and attraction by roadside salt pools in moose: an agent-based model to assess measures for reducing moose-vehicle collisions. Ecological Modeling 222:1423-1435.

Happe, P.J. 1982. The use of suburban habitats by Columbian black-tailed deer. Master's thesis, Oregon State University, Corvallis, OR.

Heydon, M.J., J.C. Reynolds, and M.J. Short. 2000. Variation in abundance of foxes (Vulpes vulpes) between three regions of rural Britain, in relation to landscape and other variables. Journal of Zoology 251:253-264.

KoganezaWA, M., AND Y. Li. 2002. Sika deer response to spotlight counts: implications for distance sampling of population density. Mammal Study 27:95-99.

Kremsater, L.L., and F.L. Bunnell. 1992. Testing responses to forest edges: the example of blacktailed deer. Canadian Journal of Zoology 70: 2426-2435.

LaUCKhaRT, J.B. 1950. Determining the big-game population from the kill. North American Wildlife Conference 15:644-650.

Long, E., K. Taylor, L. Davies, and S. Irvin. 2009. Estimating population size and movement pattern of black-tailed deer on Blakely Island, Washington. Western States and Provinces Deer and Elk Workshop 8:15.

MARQues, T.A. 2007. Incorporating measurement error and density gradients in distance sampling surveys. Doctoral dissertation, University of St. Andrews, Fife, Scotland, United Kingdom.

Marques, T.A., S.T. Buckland, R. Bispo, and B. HowLAND. 2013. Accounting for animal density gradients using independent information in distance sampling surveys. Statistical Methods and Applications 22: $67-80$.

Martin, T.G., P. Arcese, and N. Scheerder. 2011. Browsing down our natural heritage: deer impacts on vegetation structure and songbird populations 
across an island archipelago. Biological Conservation 144:459-469.

MCCoy, R., AND J. GaLlie. 2005. Final report for blacktailed deer research. Administration for Native Americans 90NR0180. Makah Forestry, Neah Bay, WA.

McCoy, R.H., S.L. Murphie, M. Szykman Gunther, AND B.L. MurphiE. 2014. Influence of hair loss syndrome on black-tailed deer fawn survival. Journal of Wildlife Management 78:1177-1188.

McCullough, D.R., K.W. Jennings, N.B. Gates, B.G. Elliott, AND J.E. Didonato. 1997. Overabundant deer populations in California. Wildlife Society Bulletin 25:478-483.

McCullough, D.R., F.W. Weckerly, P.I. Garcia, and R.R. EvetT. 1994. Sources of inaccuracy in blacktailed deer herd composition counts. Journal of Wildlife Management 58:319-329.

McShea, W.J., C.M. Stewart, L. Kearns, and S. Bates. 2011. Road bias for deer density estimates at 2 national parks in Maryland. Wildlife Society Bulletin 35:177-184.

Morelle, K., P. Bouché, F. Lehaire, V. Leeman, and P. Lejeune. 2012. Game species monitoring using road-based distance sampling in association with thermal imagers: a covariate analysis. Animal Biodiversity and Conservation 35:253-266.

Munro, K.G., J. Bowman, And L. Fahrig. 2012. Effect of paved road density on abundance of white-tailed deer. Wildlife Research 39:478-487.

Naugle, D.E., J.A. Jenks, and B.J. Kernohan. 1996. Use of thermal infrared sensing to estimate density of white-tailed deer. Wildlife Society Bulletin 24: $37-43$.

Pierce, B.L. 2000. A non-linear spotlight line transect method for estimating white-tailed deer population densities. Master's thesis, Southwest Texas State University, San Marcos, TX.

R Development Core Team. 2014. R: a language and environment for statistical computing. R Foundation for Statistical Computing, Vienna, Austria.

Roseberry, J.L., AND A. Woolf. 1991. A comparative evaluation of techniques for analyzing white-tailed deer harvest data. Wildlife Monographs 117:3-59.

Rost, G.R., AND J.A. BaILEy. 1979. Distribution of mule deer and elk in relation to roads. Journal of Wildlife Management 43:634-641.

SMiTH, I.D. 1968. The effects of hunting and seral succession upon Vancouver Island black-tailed deer. Master's thesis, University of British Columbia, Vancouver, Canada.

SMITH, W.P. 1981. Status and habitat use of Columbian white-tailed deer in Douglas County, Oregon. Doc- toral dissertation, Oregon State University, Corvallis, OR.

Sмiтh, W.P. 1987. Dispersion and habitat use by sympatric Columbian white-tailed deer and Columbian black-tailed deer. Journal of Mammalogy 68: 337-347.

Stainbrook, D.P. 2011. Methods of estimating whitetailed deer abundance at Gettysburg National Military Park: testing assumptions of distance sampling. Master's thesis, Pennsylvania State University, State College, PA.

Stainbrook, D.P. 2013. Estimating white-tailed deer abundance at the Blue Hills Reservation using distance sampling. Commonwealth of Massachusetts Division of Fisheries and Wildlife, Westborough, MA.

Thomas, L., S.T. Buckland, E.A. Rexstad, J.L. LaAke, S. Strindberg, S.L. Hedley, J.R. Bishop, T.A. Marques, and K.P. Burnham. 2010. Distance software: design and analysis of distance sampling surveys for estimating population size. Journal of Applied Ecology 47:5-14.

United States Census Bureau. 2010. Landing page. https://www.census.gov

Uno, H., K. Kaji, T. Saitoh, H. Matsuda, H. Hirakawa, K. Yamamura, and K. Tamada. 2006. Evaluation of relative density indices for sika deer in eastern Hokkaido, Japan. Ecological Research 21:624-632.

Ward, A.I., P.C.L. White, and C.H. Critchley. 2004. Roe deer Capreolus capreolus behaviour affects density estimates from distance sampling surveys. Mammal Review 34:315-319.

[WDFW] Washington Department of Fish and WILDLIFE. 2014. 2014 Game status and trend report. Olympia, WA

White, G.C., And R.M. Bartmann. 1983. Estimation of survival rates from band recoveries of mule deer in Colorado. Journal of Wildlife Management 47: $506-511$

WingaRD, R. 2015. Abundance, density, and opinions about Columbian black-tailed deer, Whidbey Island, Washington. Master's thesis, University of Montana, Missoula, MT.

Zern, E., AND R. Wells. 1955. To save the herd: shoot more deer. Sports Illustrated (21 November 1955): $24-27$.

Received 23 July 2018

Revised 11 December 2018

Accepted 18 January 2019

Published online 26 September 2019 